\title{
Development of a Chemical-Kinetic Mechanism of a Four- Component Surrogate Fuel for RP-3 Kerosene
}

\author{
Binbin Yu, Xinsheng Jiang, Donghai He, Chunhui Wang, Zituo Wang, Yunxiong Cai, Jin Yu,* \\ and Jia-jia Yu
}

Cite This: ACS Omega 2021, 6, 23485-23494

Read Online

ABSTRACT: RP-3 kerosene is the most widely used aviation kerosene in China, and research on its chemical-kinetic mechanism is significant for understanding the combustion characteristics. Based on a novel fourcomponent surrogate fuel consisting of $n$-dodecane, 2,5-dimethylhexane, $1,3,5$-trimethylbenzene, and decalin $(54,22,14$, and $10 \%$ by mole), the detailed chemical-kinetic mechanism of the corresponding RP-3 surrogate fuel with 1333 species and 6803 reactions has been developed and then reduced to 145 species and 818 reactions for high-temperature conditions. After that, the merged surrogate mechanism of surrogate fuel was validated by various experimental data sets for each individual surrogate component. Then, the surrogate mechanism was validated by comparing the simulation and experimental data of the ignition delay times, species concentrations in a jet-stirred reactor, and laminar flame speeds. Good agreements between
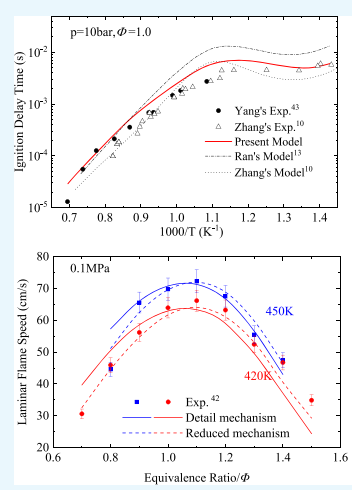
simulations and experiments were observed. In addition, using the sensitivity analysis method, the key reactions of RP-3 surrogate fuels were compared and analyzed. In summary, the mechanism developed in this study can accurately predict the ignition, oxidation, and flame propagation characteristics of RP-3 aviation kerosene. The novel surrogate model can help deeply understand the combustion characteristics of RP-3 aviation kerosene, and it is used for high-precision numerical simulation of combustion reaction flow.

\section{INTRODUCTION}

Aviation kerosene is the major fuel of aero-engines because of its high heat value and stable thermodynamic character. It is composed by hundreds and even thousands of hydrocarbons, and the composition is different as its grade differs. ${ }^{1}$ Among all kinds of aviation kerosene, RP-3 is used the most extensively in China. Additionally, its main components are alkanes, naphthenes, aromatics, and so on. ${ }^{2,3}$ Due to the difference in composition, RP-3 is different from other types of aviation kerosene such as Jet $\mathrm{A},{ }^{4}$ Jet $\mathrm{A}-1,{ }^{5}$ and $\mathrm{JP}-8^{6,7}$ in chemical and physical properties. Thus, research on the combustion characteristics of RP-3 aviation kerosene should be based on its own chemical-kinetic mechanism.

RP-3 aviation kerosene comprises a large amount of components, and some components are difficult to identify. So, it is impractical to incorporate all components and their reactions into a detailed numerical simulation of its combustion process. In addition, only a part of the components can greatly affect the combustion characteristics of aviation kerosene. ${ }^{8}$ So, it is a reasonable consideration to choose some accessible hydrocarbons to blend as surrogate fuel to predict characteristic parameters of RP-3 aviation kerosene. Some of the previous works for RP-3 surrogate fuel are collected in Table 1.
As mentioned above, many kinds of proportions of aviation kerosene surrogate fuels have been proposed and the corresponding detailed chemical-kinetic mechanisms have been established. Those studies greatly promoted the development of the CFD (computational fluid dynamics) simulation in aero-engines. The combustion characteristics including ignition, flame propagation, and species concentrations in a flow reactor are crucially important in the simulation, and a large number of experiments have been done by predecessors $^{10,15}$ to provide data for the verification of the mechanism. However, up to now, the RP-3 surrogate fuels that can comprehensively and accurately reflect the combustion characteristics have not been proposed. Thus, the construction method of surrogate fuel becomes a hotspot of research, such as the representative composition substitution method ${ }^{16}$ and parameter matching substitution method. ${ }^{17}$ They were widely adopted in the formulation of surrogate fuel mixtures.

Received: July 3, 2021

Accepted: August 13, 2021

Published: September 1, 2021 
Table 1. Previous Works of Surrogate Fuel for RP-3 Aviation Kerosene

\begin{tabular}{|c|c|}
\hline composition (\% mol) & comment \\
\hline $\begin{array}{l}N \text {-decane }(100 \%) \\
N \text {-decane }(88.7 \%) \\
1,2,4- \\
\text { trimethylbenzene } \\
(11.3 \%)\end{array}$ & $\begin{array}{l}\text { It only applies to the combustion simulation of a lean fuel/air ratio. } \\
\text { It has been validated at a wide temperature range at } 10 \mathrm{~atm}^{10}\end{array}$ \\
\hline $\begin{array}{l}N \text {-dodecane }(65 \%) \\
N \text {-tetradecane }(10 \%) \\
\text { decalin }(25 \%)\end{array}$ & $\begin{array}{l}\text { It can perform well in a } \mathrm{H} / \mathrm{C} \text { ratio, density, and molecular weight. The laminar flame speed at } 0.1 \mathrm{MPa}, 420 \text { and } 460 \mathrm{~K} \text {, and an equivalence } \\
\text { ratio range from } 0.7 \text { to } 1.4 \text { match well with the targeted kerosene. }\end{array}$ \\
\hline $\begin{array}{l}\text { toluene }(15.0 \%) \\
\text { trans-decane }(18.9 \%) \\
N \text {-decane }(59.1 \%) \\
\text { isohexadecane } \\
\quad(7.0 \%)\end{array}$ & $\begin{array}{l}\text { It can be used to simulate the ignition delay time (IDT) at } 1 \mathrm{~atm} \text { in a high-temperature range and at } 10 \text { atm in a wide temperature range as } \\
\text { well as a laminar flame speed of } 403 \mathrm{~K} \text { and } 1 \mathrm{~atm} .{ }^{13}\end{array}$ \\
\hline $\begin{array}{l}N \text {-decane }(14 \%) \\
N \text {-dodecane }(10 \%) \\
\text { isohexadecane }(30 \%) \\
\text { methylcyclohexane } \\
\quad(36 \%) \\
\text { toluene }(10 \%)\end{array}$ & $\begin{array}{l}\text { The molecular mass, hydrogen-carbon ratio, cetane number, and lower heating value of the surrogate fuel agree well with the corresponding } \\
\text { criteria of RP-3 kerosene. Additionally, it performs well in the variation trend of densities and kinematic viscosities. }\end{array}$ \\
\hline
\end{tabular}

However, in those substitution methods, the formulation is realized by matching some phenomenological and macroscopic property characters, which is highly empirical and crude. Constitutionally, the microcosmic molecular structure of practical fuel is the key factor in the macroscopic property. Therefore, based on that consideration, the FGBS (function group-based surrogate fuel) methodology ${ }^{18,19}$ has been proposed. A previous study has proven that it is a rather efficient methodology to obtain the surrogate formulation with high accuracy. ${ }^{20}$

In our early work, ${ }^{21}$ based on the FGBS methodology, the four-component surrogate fuel consisting of $n$-dodecane, 2,5dimethylhexane, 1,3,5-trimethylbenzene, and decalin (54, 22, 14 , and $10 \%$ by mole) has been proposed, and it can well reflect the main physical properties of RP-3 kerosene from subcritical to supercritical pressures. Yet, research on its chemical properties is not enough. In this study, a chemicalkinetic mechanism of this four-component surrogate fuel is developed and then validated against the ignition delay time (IDT), oxidation experiment, and laminar flame speed in a wide extent of conditions, and sensitivity analysis is also performed to reveal the constitutional behavior of RP-3 combustion and get deep insight into the mechanism of surrogate fuels.

\section{DEVELOPMENT OF CHEMICAL-KINETIC MECHANISMS}

The surrogate fuel, $n$-dodecane, 2,5-dimethylhexane, 1,3,5trimethylbenzene, and decalin $(54,22,14$, and $10 \%$ by mole), is obtained by the FGBS methodology with comprehensive consideration after quantifying the molecular structure by the functional groups of $\mathrm{CH}_{3}, \mathrm{CH}_{2}, \mathrm{CH}$, and phenyl. The MWs (molar weights) and hydrogen/carbon $(\mathrm{H} / \mathrm{C})$ molar ratios of the surrogate fuel and RP-3 aviation kerosene match well as shown in Table 2. In addition, the parameters density, viscosity, specific heat, and heat conductivity coefficient also match well with the experimental data as our early work shows in ref 19.

$\mathrm{N}$-Dodecane was chosen as a surrogate component because it can reflect the physical and chemical properties of linear alkanes and provide $\mathrm{CH}_{3}$ and $\mathrm{CH}_{2}$ functional groups. The $n$ -
Table 2. Molar Masses and H/C Ratios of RP-3 Aviation Kerosene and Its Surrogate Fuel

\begin{tabular}{lcc}
\multicolumn{1}{c}{ fuel } & molar weight $\left(\mathrm{g} \cdot \mathrm{mol}^{-1}\right)$ & $\mathrm{H} / \mathrm{C}$ ratio \\
$\mathrm{RP}^{2}{ }^{2}$ & 148.8 & 2.08 \\
surrogate fuel & 147.5 & 2.06 \\
\hline
\end{tabular}

dodecane-optimized mechanism of Cai et al. ${ }^{22}$ is chosen in this study. 2,5-Dimethylhexane can characterize the physicochemical properties of branched alkanes. Its mechanism, which was developed by Sarathy et al., ${ }^{23}$ has been selected in this study. 1,3,5-Trimethylbenzene represents aromatics, and its mechanism was chosen from the literature. ${ }^{24}$ Additionally, decalin represents naphthenes with its mechanism chosen from the work of Fang et al. ${ }^{25}$

Due to a great deal of previous studies on the chemicalkinetics of small molecular hydrocarbon fuels, the reaction mechanisms of small molecular hydrocarbon fuels have been widely accepted and used, which can be adopted into the fourhydrocarbon components in this research. According to those above, the mechanism of RP-3 aviation kerosene was developed by integrating the small molecular mechanism and the high-molecular-weight fuel mechanisms. Thus, a detailed chemical-kinetic mechanism of RP-3 aviation kerosene with 1333 species and 6803 reactions was obtained by adding the large molecular reaction pathways into the AramcoMech 2.0 $\mathrm{C}_{0}-\mathrm{C}_{4}$ core mechanism ${ }^{26}$ and eliminating the reduplicative and redundant species and reactions. In the elimination, the selections of thermodynamic parameters and chemical reaction rate constants obey the preferential order as their proportions: $n$-dodecane $>2,5$-dimethylhexane $>1,3,5$-trimethylbenzene $>$ decalin. All the rate coefficients of reactions were kept consistent with the corresponding original chemical-kinetic mechanisms.

As we all know, the detailed chemical-kinetic mechanism is not suitable for the numerical simulation. The huge amount of computation increases computing cost and reduces its efficiency. So, it is really necessary to reduce the size of the chemical-kinetic mechanism of RP-3 aviation kerosene surrogate fuel. The directed relation $\operatorname{graph}^{27}$ is used in the mechanism reduction based on the Chemkin-Pro software. ${ }^{28}$ 

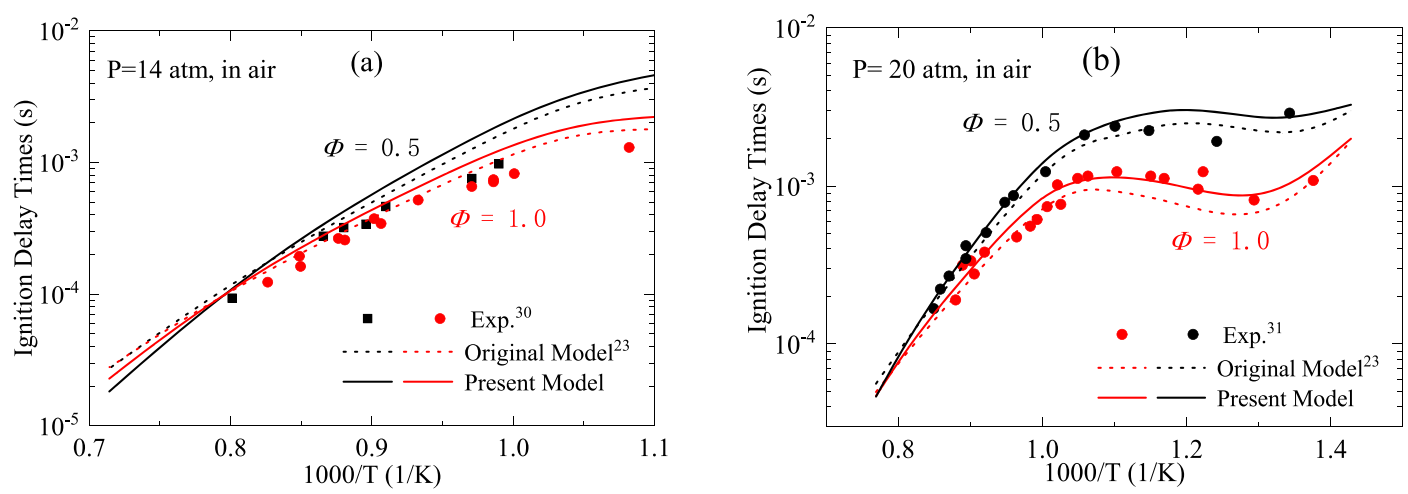

Figure 1. Comparison between calculated and experimental IDTs of $n$-dodecane. (a) $p=14$ atm and (b) $p=20$ atm. Symbols represent the experimental values of IDTs. ${ }^{29,30}$ Solid lines represent the calculated IDTs of the present surrogate mechanism. Dotted lines represent the calculated IDTs of the original mechanism. ${ }^{22}$

The ignition delay time was chosen as the target at temperatures of $1200,1400,1600$, and $1800 \mathrm{~K}$ and equivalence ratios of $0.5,1.0$, and 1.5 under a pressure of $1 \mathrm{~atm}$. The reduced model size was then modulated only by changing the threshold value incrementally from 0.01 to 0.2 . Finally, the simplified chemical-kinetic mechanism of RP-3 aviation kerosene surrogate fuel contained 129 species and 813 reactions.

\section{RESULTS AND DISCUSSION}

3.1. Validation of the Component Mechanism in the Surrogate Mechanism. The chemical-kinetic mechanism of RP-3 aviation kerosene surrogate fuel includes the chemicalkinetic mechanisms of the four basic fuels. So, it must perform well in predicting the combustion characteristic of each basic fuel. In this study, CHEMKIN Pro was used to calculate the IDTs, laminar flame speeds, and the concentrations of products in the jet-stirred reactor of the four components, and the calculation results were contrasted with the corresponding experimental results.

3.1.1. $n$-Dodecane. The IDTs of $n$-dodecane calculated by the detailed chemical-kinetic mechanism of RP-3 aviation kerosene surrogate fuel under the pressures of 14 and $20 \mathrm{~atm}$ and equivalence ratios of 0.5 and 1.0, respectively, are shown in Figure 1. The results of the original mechanisms and experiments $^{29,30}$ are added for comparison. It is observed that the calculated IDTs are approximate to the experimental ones, and the negative temperature coefficient (NTC) effect behavior is reflected satisfactorily as shown in Figure $1 \mathrm{~b}$, especially at an equivalence ratio of 1.0. Comparing with the original $n$-dodecane mechanism, the accuracy of the present surrogate mechanism decreases very slightly under a pressure of $14 \mathrm{~atm}$, while the disparity between IDTs calculated by the present surrogate mechanism and experimental data is smaller than that between the original and experimental data under a pressure of $20 \mathrm{~atm}$.

Figure 2 shows the comparison between the calculated and experimental laminar flame speeds ${ }^{31}$ of $n$-dodecane under a temperature of $403 \mathrm{~K}$ and a pressure of 1 atm. It can be observed that the calculations of the present surrogate mechanism are more approximate to the experimental values, and the present surrogate mechanism can exactly reveal the flame propagation characteristics of $n$-dodecane under the conditions above.

3.1.2. 2,5-Dimethylhexane. According to the conditions of the experiments in the literature, ${ }^{23}$ the IDTs of 2,5-

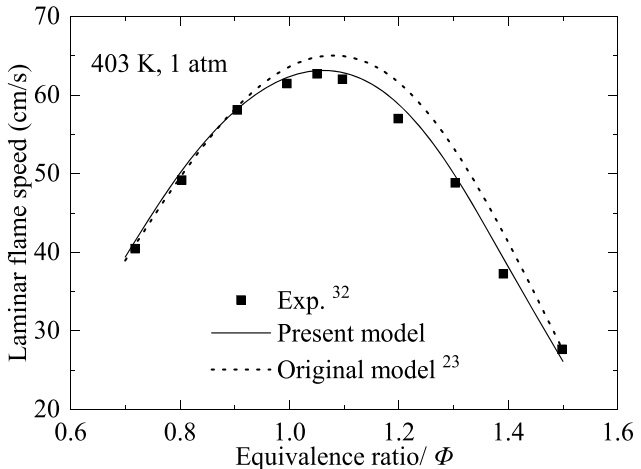

Figure 2. Comparison between the calculated and experimental laminar flame speeds of $n$-dodecane. Symbols represent experimental values of the laminar flame speed. ${ }^{31}$ The solid line represents the calculated results of the present model. The dotted line represents the calculated results of the original model. ${ }^{22}$

dimethylhexane were calculated, and the results are shown in Figure 3 together with the corresponding experimental results and calculated results of the original mechanism. ${ }^{23}$ It can be seen that the results calculated by the present surrogate model are close to the experimental ones, even though they are a bit higher than the results calculated by the original mechanism in the NTC region under a pressure of $20 \mathrm{~atm}$. The difference may be caused by the substitution of the $\mathrm{C}_{0}-\mathrm{C}_{4}$ core mechanism, such as the reactions between $\mathrm{C}_{3} \mathrm{H}_{6}$ and $\mathrm{O}_{2}$, which have an inhibiting effect on ignition, especially in the low-temperature region, yet their reaction coefficients are different in the original mechanism compared with the present surrogate mechanism. In general, the chemical-kinetic mechanism of RP-3 aviation kerosene surrogate fuel developed in this study can predict the IDT well in the conditions mentioned above.

Figure 4 shows the mole fractions of $\mathrm{O}_{2}, \mathrm{CO}, \mathrm{H}_{2} \mathrm{O}$, and $\mathrm{CO}_{2}$ from simulations and experiments, ${ }^{23}$ and those species are the oxidation products in a jet-stirred reactor for a 2,5dimethylhexane $/ \mathrm{O}_{2} / \mathrm{N}_{2}$ mixture at a pressure of $10 \mathrm{~atm}$, equivalence ratio of 1.0 , and residence time of $0.7 \mathrm{~s}$. It can be seen that the variation trends of species are captured by the present surrogate mechanism, and the calculated values are close to the experimental ones, the present surrogate mechanism performs better in predicting the mole fractions of oxidation products than the original. 

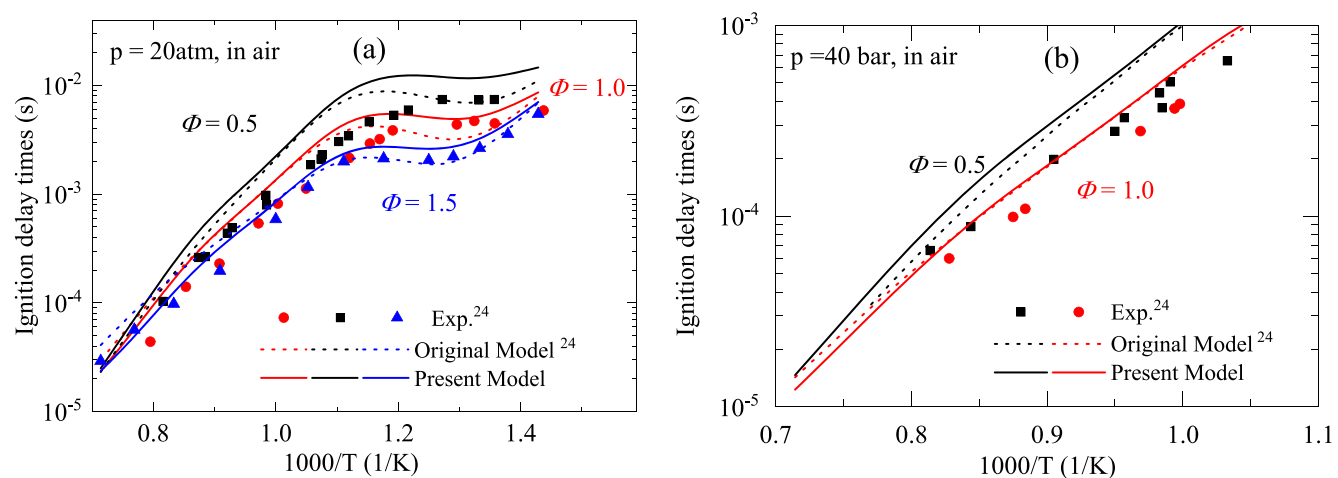

Figure 3. Comparison between the calculated and experimental IDTs of 2,5-dimethylhexane. (a) $p=20$ atm and (b) $p=20$ bar. Symbols represent experimental values of IDTs. ${ }^{23}$ Solid lines represent the calculated results of the present surrogate model. Dotted lines represent the calculated results of the original model. ${ }^{23}$

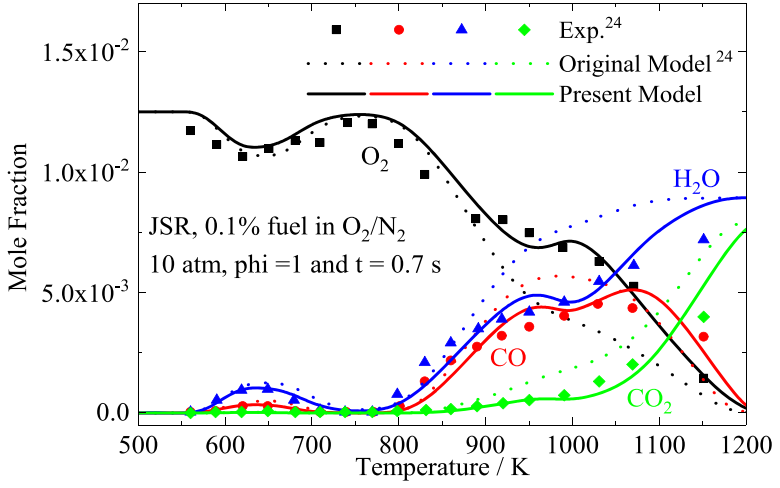

Figure 4. Comparison between the calculated and experimental mole fractions in a jet-stirred reactor of 2,5-dimethylhexane. Symbols represent experimental values. ${ }^{23}$ Solid lines represent the calculated results of the present surrogate model. Dotted lines represent the calculated results of the original model. ${ }^{23}$

3.1.3. 1,3,5-Trimethylbenzene. As shown in Figure 5, the calculated and experimental IDTs of 1,3,5-trimethylbenzene ${ }^{32}$ under the condition of a temperature range of $1100-1500 \mathrm{~K}$ are compared at equivalence ratios of 0.5 and 1.0, pressures of 10 and 20 bar. The results calculated by the present surrogate mechanism are almost the same as that by the original 1,3,5trimethylbenzene mechanism. They are reasonable under the

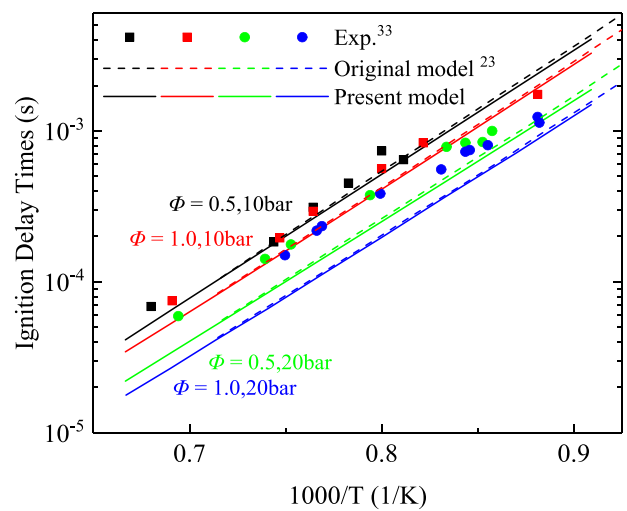

Figure 5. Contrast between the calculated and experimental IDTs of 1,3,5-trimethylbenzene. Symbols represent experimental values of $\mathrm{IDT}^{32}$ Solid lines represent the calculated IDTs of the present surrogate model. Dotted lines are the calculated results of the original model. $^{24}$ conditions above, yet the calculated values are marginally greater than the experimental values. The simulation is more accurate under a pressure of 10 bar than 20 bar.

Figure 6 shows the comparison between the calculated and experimental laminar flame speeds of 1,3,5-trimethylbenzene ${ }^{31}$

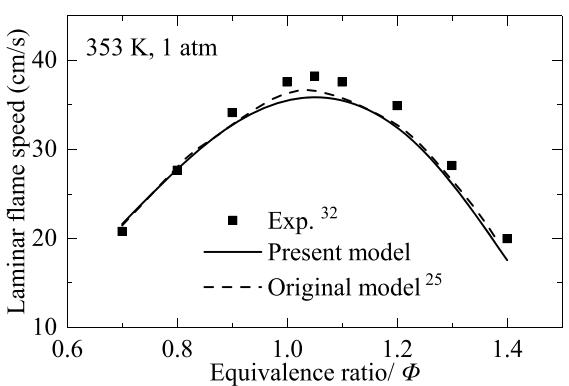

Figure 6. Comparison between the calculated and experimental laminar flame speeds of 1,3,5-trimethylbenzene. Symbols represent experimental values. ${ }^{31}$ Solid lines represent the calculated results of the present surrogate model. Dotted lines represent the calculated results of the original model. ${ }^{24}$

at a pressure of $1 \mathrm{~atm}$ and a temperature of $353 \mathrm{~K}$. It is observed that the calculation results of the present and original 1,3,5-trimethylbenzene mechanisms are almost the same except the peaks of the laminar flame speed. Both the present and original 1,3,5-trimethylbenzene mechanisms can reflect the variation tendency of the laminar flame speed at equivalence ratios from 0.7 to 1.4 .

3.1.4. Decalin. The IDTs of decalin calculated by the chemical-kinetic mechanism of RP-3 aviation kerosene surrogate fuel and the original decalin mechanism are compared with the previous experimental data ${ }^{33,34}$ in Figure 7. As shown in the figure, the present surrogate mechanism performs well in predicting the IDTs of decalin at equivalence ratios of 0.5 and 1.0, pressures of 12 and 20 atm, and a temperature range of $900-1300 \mathrm{~K}$. The NTC behaviors are observed around the temperatures of $750-900 \mathrm{~K}$, and the present surrogate mechanism performs better than the original decalin mechanism.

Figure 8 shows the contrast between the calculated and experimental laminar flame speeds ${ }^{35,36}$ of decalin at different equivalent ratios, the pressure is $1 \mathrm{~atm}$, and the temperatures are 403 and $443 \mathrm{~K}$. It is seen that the chemical-kinetic mechanism of RP-3 aviation kerosene surrogate fuel can perform well in the prediction of flame propagation of decalin. 

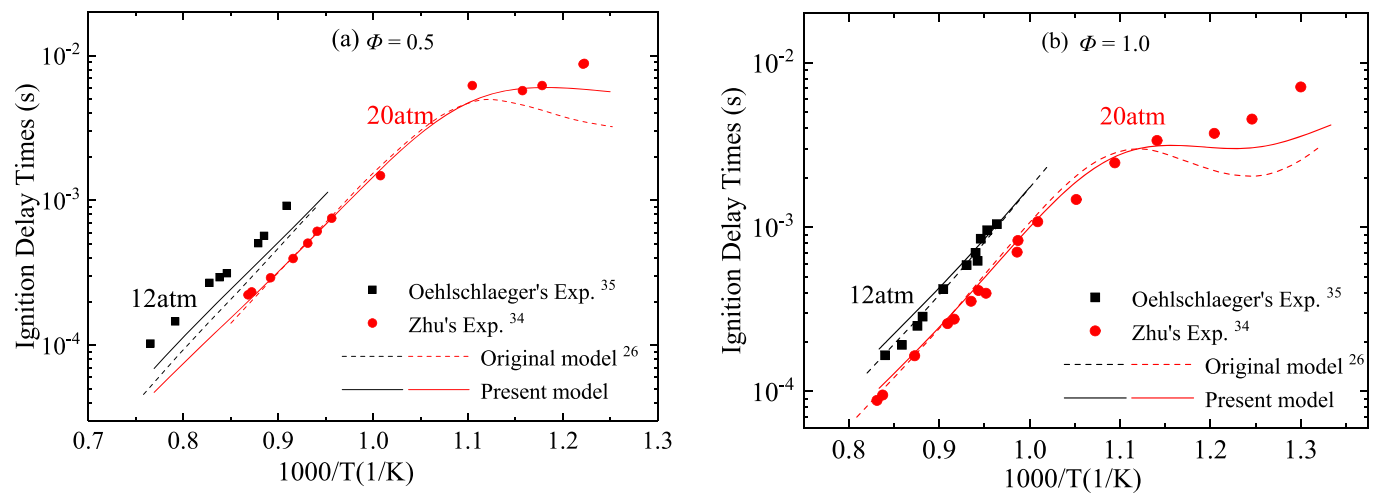

Figure 7. Comparison between the calculated and experimental IDTs of decalin. (a) $\Phi=0.5$ and (b) $\Phi=1.0$. Symbols represent experimental values of IDTs. ${ }^{33,34}$ Solid lines represent the calculated IDTs of the present surrogate model. Dotted lines represent the calculated IDTs of the original model. $^{25}$

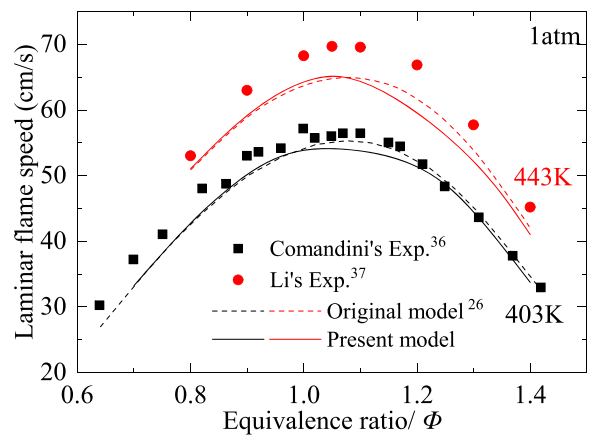

Figure 8. Comparison between the calculated and experimental laminar flame speeds of decalin. Symbols represent experimental values. ${ }^{35,36}$ Solid lines represent the calculated results of the present surrogate model. Dotted lines represent the calculated results of the original model. $^{25}$

The values from the original surrogate mechanism are closer to the experimental ones than those from the present surrogate model, yet the equivalence ratio corresponding to the peaks from the present surrogate mechanism is more accurate than that from the original.

3.2. Validation and Analysis of the Surrogate Mechanism. In order to validate the RP-3 aviation kerosene surrogate mechanism, the simulation calculation was undertaken and the results were compared with the previous experimental results, which are summarized in Table 3.

Table 3. Previous Experimental Results on RP-3 Kerosene Used for Validation

\begin{tabular}{|c|c|c|c|}
\hline $\begin{array}{c}\text { type of } \\
\text { experiment }\end{array}$ & conditions & type of data & reference \\
\hline shock tube & $\begin{array}{l}T=1100-1600 \mathrm{~K} ; p=0.1 \\
0.2 \text {, and } 0.3 \mathrm{MPa} ; \Phi= \\
0.5,1.0 \text {, and } 1.5\end{array}$ & $\begin{array}{l}\text { ignition delay } \\
\text { time }\end{array}$ & $\begin{array}{l}\text { Liu et } \\
\text { al. }\end{array}$ \\
\hline $\begin{array}{l}\text { shock tube rapid } \\
\text { and } \\
\text { compression } \\
\text { machine }\end{array}$ & $\begin{array}{r}T=624-1437 \mathrm{~K} ; p=10 \\
15,20 \mathrm{~atm} ; \Phi=0.5-1.5\end{array}$ & $\begin{array}{l}\text { ignition delay } \\
\text { time }\end{array}$ & $\begin{array}{l}\text { Mao et } \\
\text { al. }^{38}\end{array}$ \\
\hline shock tube & $\begin{array}{l}T=920-1700 \mathrm{~K} ; p=2,10 \\
\quad \text { bar; } \Phi=0.5,1.0 \text {, and } 2.0\end{array}$ & $\begin{array}{l}\text { ignition delay } \\
\text { time }\end{array}$ & $\begin{array}{l}\text { Yang et } \\
\text { al. }^{39}\end{array}$ \\
\hline jet-stirred reactor & $\begin{array}{l}T=500-1100 \mathrm{~K} ; p=1 \\
\quad \text { atm } ; \Phi=2\end{array}$ & $\begin{array}{l}\text { oxidized } \\
\text { intermediates } \\
\text { and products }\end{array}$ & $\mathrm{Liu}^{40}$ \\
\hline $\begin{array}{l}\text { constant volume } \\
\text { chamber }\end{array}$ & $\begin{array}{l}T=420 \text { and } 450 \mathrm{~K} ; p=0.1 \\
\mathrm{MPa} ; \Phi=0.7-1.5\end{array}$ & $\begin{array}{l}\text { laminar flame } \\
\text { speed }\end{array}$ & $\begin{array}{l}\text { Liu et } \\
\text { al. }\end{array}$ \\
\hline
\end{tabular}

3.2.1. Ignition Delay Validation of the Detailed Mechanism. The IDTs of RP-3 aviation kerosene were calculated at pressures of $0.1,0.2$, and $0.3 \mathrm{MPa}$; at a temperature region of $1100-1600 \mathrm{~K}$; and equivalent ratios of $0.5,1.0$, and 1.5 . The results are compared with Liu et al.'s experimental data ${ }^{37}$ as shown in Figure 9. It shows obviously that the IDTs calculated by the detailed mechanism of RP-3 aviation kerosene's surrogate fuel are linear with the reciprocal value of the temperature under the simulation conditions mentioned above, which conforms to the Arrhenius law. Additionally, both the change trends and values of simulated IDTs fit well with the experimental data, especially when the equivalent ratios are 0.5 and 1.0, and thus the simulation results are satisfactory.

For the purpose of verifying the detailed mechanism constructed in a wide temperature range, especially under the condition of lower temperatures, the simulation calculation of IDT was carried out according to Mao et al.'s, Yang et al.'s, and Zhang et al.'s experimental conditions. ${ }^{10,38,39}$ The simulations of the IDT of the surrogate fuel were calculated under the conditions of equivalent ratios of $0.5,1.0$, and 1.5, and the results are compared with the experimental values as shown in Figure 10. The IDTs calculated by mechanisms in previous studies ${ }^{10,13}$ are added in Figure 10 for comparison. It can be seen that the RP-3 aviation kerosene IDT calculation and experimental results agree in trends and specific points under a pressure of 10 bar. The simulation result of a 1.5 equivalent ratio is more accurate in the high-temperature region, and the simulation result of a 1.0 equivalent ratio is more accurate in the NTC region. The IDTs simulated in this study are closer to the experimental data both in changing trends and values than the previous. Especially when the equivalent ratio is 1.0, the curve obtained from the simulation calculation almost passes the points of the experimental values in the NTC region. The results present a stronger ability to predict the IDT than the previous with high accuracy.

In order to analyze the chemical-kinetic mechanism of RP-3 aviation kerosene surrogate fuel further and know its combustion process from the essence, sensitivity analysis of IDT was performed at atmospheric pressure, an equivalent ratio of 1.0 , and temperatures of 800,1200 , and $1600 \mathrm{~K}$, as shown in Figure 11. The sensitivity coefficient is defined as sensitivity $\%=\left(T_{2 \mathrm{k} i}-T_{\mathrm{k} i}\right) / T_{\mathrm{k} i} \times 100 \%$, where $T_{\mathrm{k} i}$ is the IDT of the original reaction and $T_{2 \mathrm{k} i}$ is the IDT after doubling the rate constant value of the $i$ th reaction. If the sensitivity coefficient is positive, then it indicates that the reaction has an 

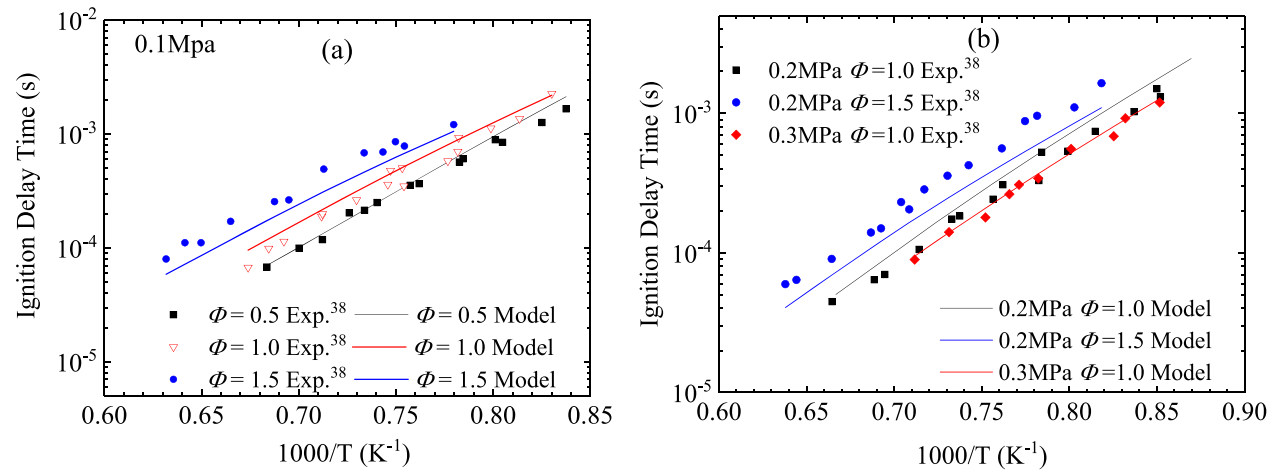

Figure 9. Comparison between the calculated data and experimental data ${ }^{37}$ of IDTs under high-temperature conditions. (a) $p=0.1 \mathrm{MPa}$ and (b) $p$ $=0.2$ and $0.3 \mathrm{MPa}$.
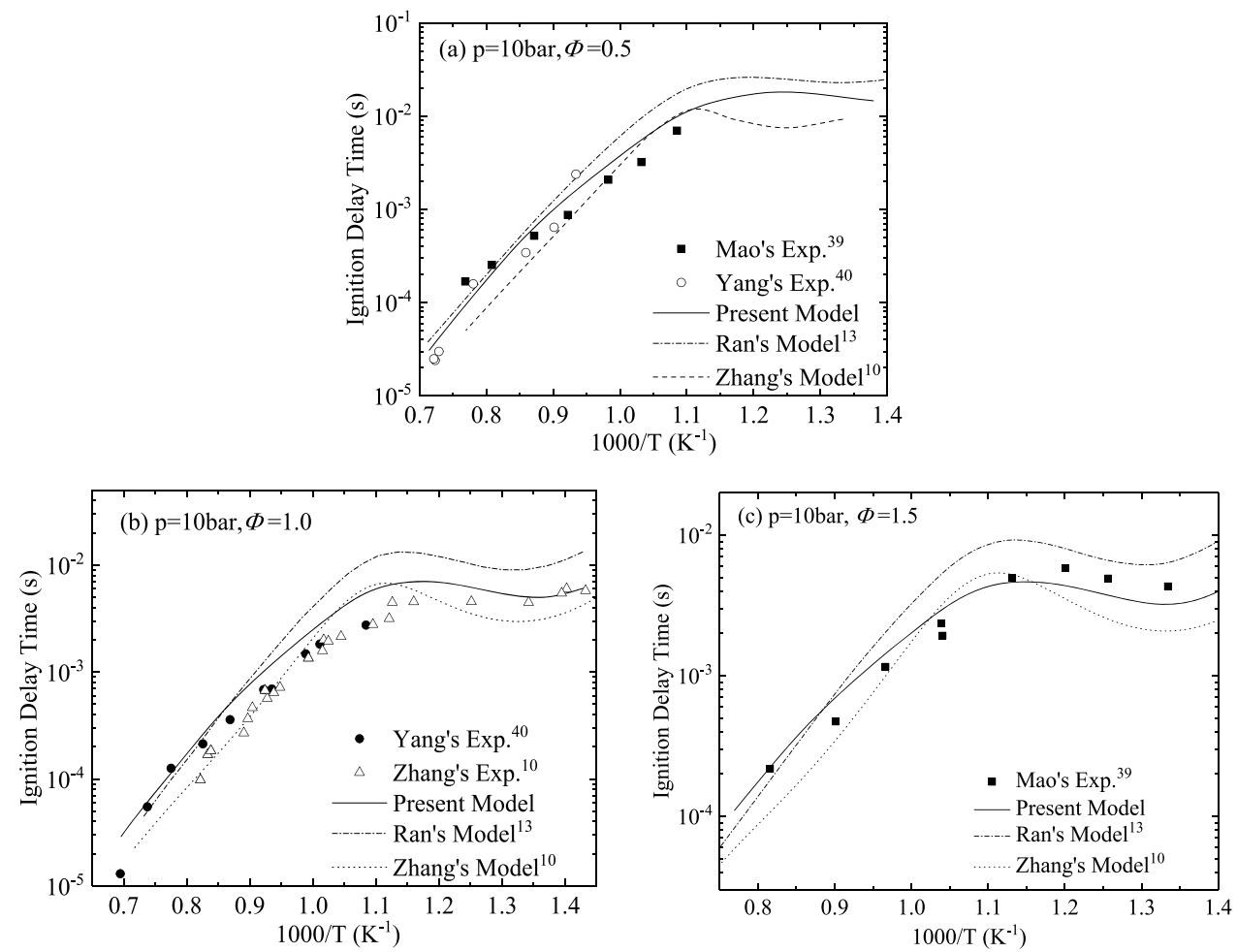

Figure 10. Comparison of calculated data of IDTs between the present model and previous models. ${ }^{10,13}$ Symbols represent experimental measurements of IDTs. ${ }^{10,38,39}$ Solid lines represent the calculated IDTs of the present surrogate model. Dotted and dotted dash lines represent the calculated IDTs of the previous models. ${ }^{10,13}$ (a) $p=10$ bar, $\Phi=0.5$; (b) $p=10$ bar, $\Phi=1.0$; and (c) $p=10$ bar, $\Phi=1.5$.

inhibitory effect on ignition, and contrariwise, it means that the reaction can promote the ignition.

Comparing the sensitivity coefficients of IDT in Figure 11, the reactions that have a great effect on ignition delay vary with temperature, and with the increase in temperature, the inhibiting effect on ignition is gradually limited, while the promoting effect is gradually prominent. Among the reactions with inhibiting effects, chain termination reactions and radical reduction reactions are the main part. As the temperature increases, the inhibiting effect of the macromolecular reactions decreases, yet $\mathrm{T} 135 \mathrm{MBZ}+\mathrm{O}_{2} \rightarrow \mathrm{T} 135 \mathrm{MBJ}+\mathrm{HO}_{2}$ always shows a considerable inhibiting effect. $\mathrm{CH}_{3}+\mathrm{HO}_{2} \rightarrow \mathrm{CH}_{4}+$ $\mathrm{O}_{2}$ is one of the reactions in the $\mathrm{C}_{0}-\mathrm{C}_{4}$ core mechanism, which inhibits ignition in a wide temperature range, especially at a temperature of $1200 \mathrm{~K}$. At a low temperature, the reactions promoting ignition are the dehydrogenation of macromolecules with $\mathrm{HO}_{2}$, especially the dehydrogenation of
$\mathrm{NC}_{12} \mathrm{H}_{26}$, and then turn to small molecule reactions, $\mathrm{O}_{2}+\mathrm{H}$ $\rightarrow \mathrm{O}+\mathrm{OH}, \mathrm{CH}_{3}+\mathrm{HO}_{2} \rightarrow \mathrm{CH}_{3} \mathrm{O}+\mathrm{OH}$, and $\mathrm{C}_{2} \mathrm{H}_{4}+\mathrm{OH} \rightarrow$ $\mathrm{C}_{2} \mathrm{H}_{3}+\mathrm{H}_{2} \mathrm{O}$ as the temperature rises to a high level. Among the three small-molecule reactions above, the first two reactions are branching chain reactions, which accelerate the combustion process. In general, $\mathrm{CH}_{3}+\mathrm{HO}_{2} \rightarrow \mathrm{CH}_{4}+\mathrm{O}_{2}$ and $\mathrm{O}_{2}+\mathrm{H} \rightarrow \mathrm{O}+\mathrm{OH}$ are the crucial reactions for IDT under atmospheric pressure.

3.2.2. Species Concentration Validations of the Detailed Mechanism. In this study, the mole fractions of oxidation products were calculated by the perfectly stirred reactor model at atmospheric pressure and an equivalent ratio of 2.0 under the condition of a temperature range of 575-1100 K according to Liu's experiment. ${ }^{40}$

The mole fractions of major products and light hydrocarbon intermediates of oxidations are shown in Figure 12. In terms of the overall situation of Figure 12, the increase and decrease in 
(a) $800 \mathrm{~K}, 1 \mathrm{~atm}, \Phi=1.0$, in air

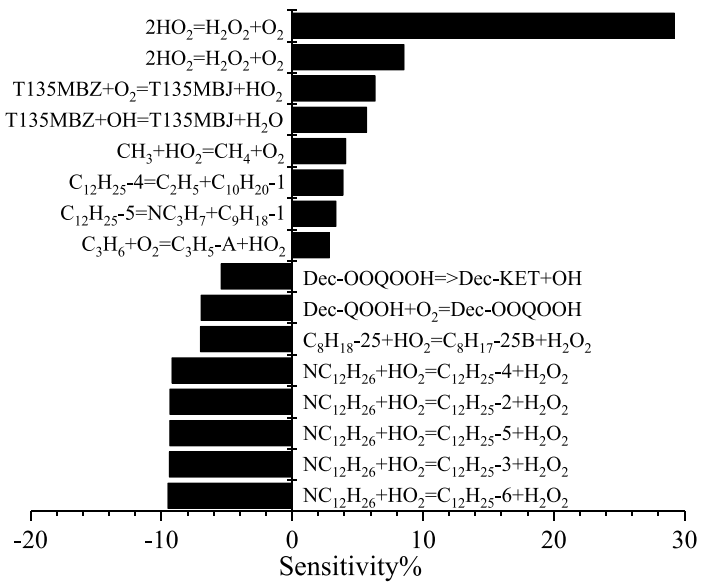

(b) $1200 \mathrm{~K}, 1 \mathrm{~atm}, \Phi=1.0$, in air

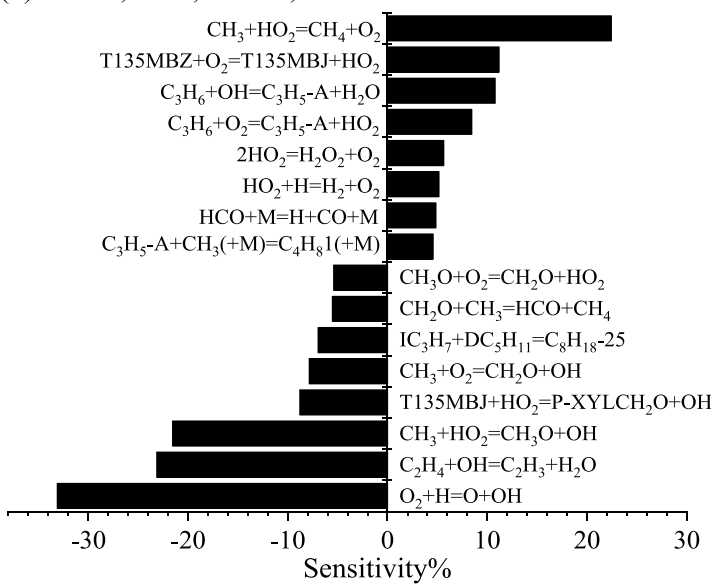

(c) $1600 \mathrm{~K}$, 1atm, $\Phi=1.0$, in air

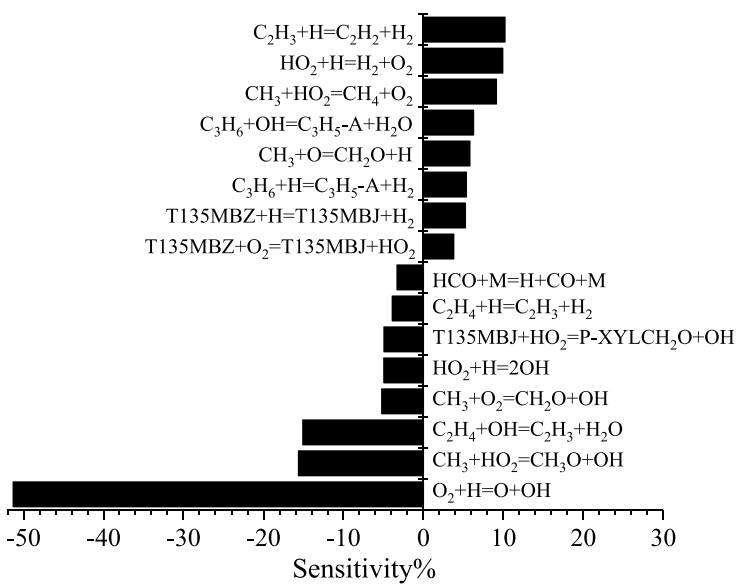

Figure 11. Sensitivity analysis of IDT under different temperatures. (a) $800 \mathrm{~K}, \Phi=1.0$, in air; (b) $1200 \mathrm{~K}, \Phi=1.0$, in air; and (c) $1600 \mathrm{~K}, \Phi=1.0$, in air.

the mole fractions of components with temperature are predicted well by the detailed mechanism of the surrogate fuel developed in this study. The ability to predict the mole fractions of oxidation products is acceptable under the temperatures of $775-1100 \mathrm{~K}$, especially the major products, whose simulation results are in consistency with the experimental results both in trends and values.

3.2.3. Validation of the Reduced Mechanism. The detailed mechanism of RP-3 aviation kerosene surrogate fuel was reduced by choosing the IDT as the target, and the prediction ability of the reduced mechanism is naturally close to the detailed mechanism as shown in Figure 13a. For further verification, the laminar flame speed of RP-3 aviation kerosene's surrogate fuel was calculated under the conditions in accordance with the experimental conditions of Liu et al. ${ }^{41}$ The simulation results of the detailed and reduced mechanism at a pressure of $0.1 \mathrm{MPa}$ and under the initial temperatures of 420 and $450 \mathrm{~K}$ are compared with the experimental results as shown in Figure 13b. It shows that change trends of the simulations are consistent with those of the experiment, and the equivalent ratio corresponding to maximum values of the laminar flame speed calculated by the reduced mechanism is closer to the experimental one than that by the detailed mechanism. A tolerance scope of $\pm 5 \%$ is added to the experimental data. It shows that the values calculated by the reduced mechanism are close to the experimental values. The errors between the reduced simulation values and the experimental values are within $\pm 5 \%$ when the equivalent ratio is within a range of $0.9-1.2$. It is suffice to say that the reduced mechanism of RP-3 aviation kerosene surrogate fuel has a good predictive ability for ignition and the laminar flame propagation speed under the conditions mentioned above.

\section{CONCLUSIONS}

Based on a novel surrogate formulation of $n$-dodecane, 2,5dimethylhexane, 1,3,5-trimethylbenzene, and decalin (54, 22, 14 , and $10 \%$ by mole), which was proposed in our previous work, ${ }^{20}$ a corresponding detailed chemical-kinetic mechanism with 1333 species and 6803 reactions was developed based on that surrogate fuel and then simplified to 136 species and 853 reactions. The surrogate mechanisms were validated against the experimental data of each component, which showed satisfactory performance under the conditions of $0.01 \mathrm{Mpa}-10$ bar, $700-1600 \mathrm{~K}$, and equivalence ratios of $0.5-2.0$.

The comparisons between simulation results and previous experimental data indicate that the detailed mechanism can predict the IDT of RP-3 aviation kerosene satisfactorily under atmospheric pressure and high-temperature conditions as well as in high-pressure and wide-temperature ranges, especially when the equivalent ratios are 0.5 and 1.0. Additionally, the sensitivity analysis indicates that $\mathrm{CH}_{3}+\mathrm{HO}_{2} \rightarrow \mathrm{CH}_{4}+\mathrm{O}_{2}$ and $\mathrm{O}_{2}+\mathrm{H} \rightarrow \mathrm{O}+\mathrm{OH}$ are the crucial reactions for IDT under atmospheric pressure. The detailed mechanism also can predict 

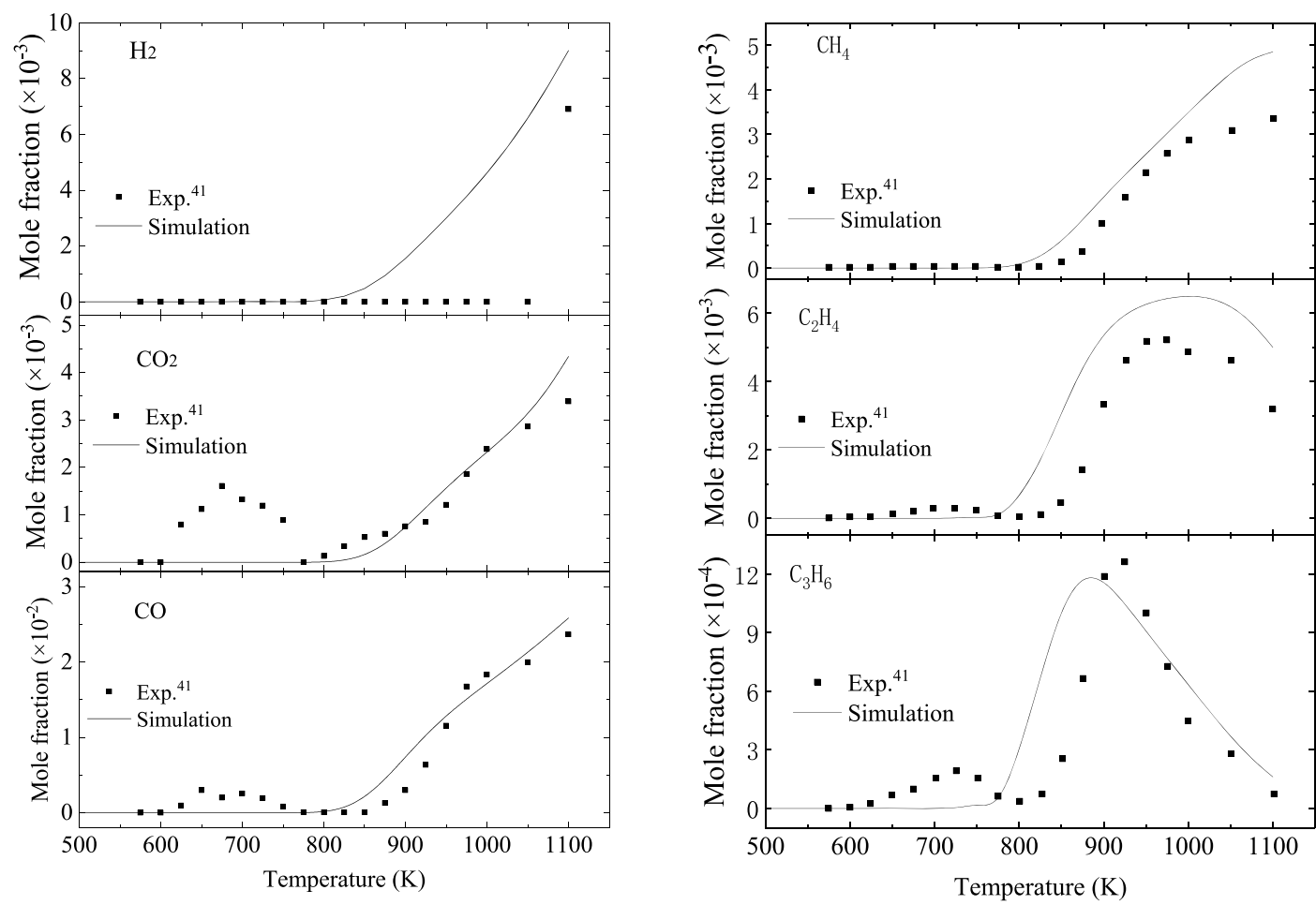

Figure 12. Calculated and experimental mole fractions of major products and light hydrocarbon intermediates of oxidations under conditions of 1 atm, $\Phi=2$, and $t=1.06$ s. Symbols represent the experimental data, ${ }^{40}$ and lines represent the calculated results.
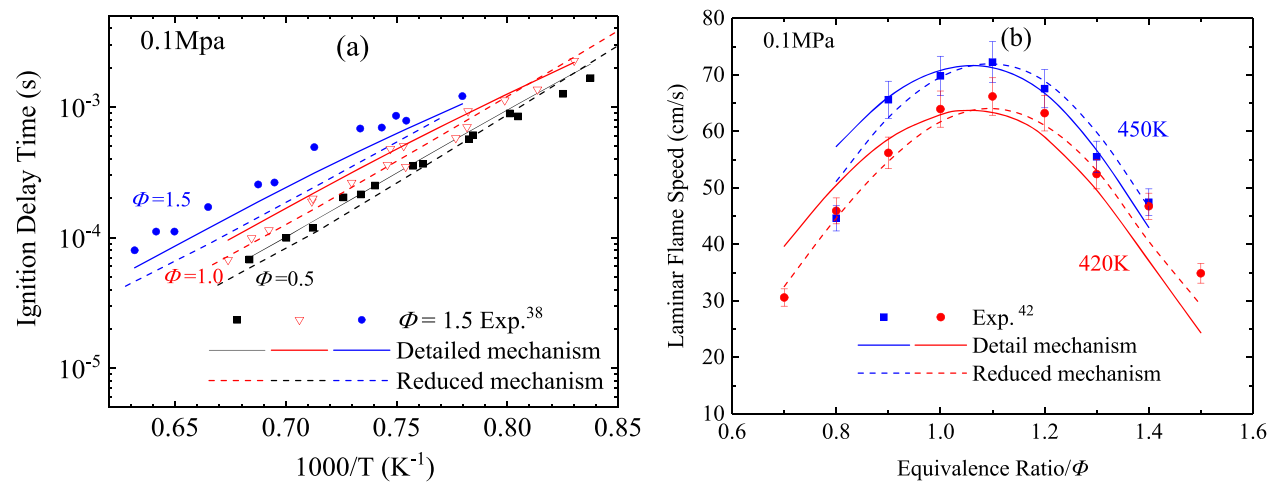

Figure 13. Comparison between the calculated and experimental results. Symbols represent the experimental data, ${ }^{37,41}$ solid lines represent the calculated results of the detailed mechanism, and dashed lines represent the calculated results of the reduced mechanism. (a) Comparison of IDTs and (b) comparison of laminar flame speeds.

the mole fractions of oxidation products reasonably. Also, the reduced mechanism of RP-3 aviation kerosene surrogate fuel has a good predictive ability for ignition and the laminar flame propagation speed under the atmospheric pressure.

From the analysis above, it can be seen that the chemical reaction mechanisms of the surrogate fuel developed and reduced in this study can reflect the ignition, oxidation, and flame propagation characteristics of RP-3 aviation kerosene. The developed surrogate model can help in understanding deeply the combustion characteristics of RP-3 aviation kerosene and be used for high-precision numerical simulation of combustion reaction flow.

\section{ASSOCIATED CONTENT}

\section{s) Supporting Information}

The Supporting Information is available free of charge at https://pubs.acs.org/doi/10.1021/acsomega.1c03442.
Detailed RP-3 aviation kerosene surrogate mechanism and its reduced mechanism (PDF)

\section{AUTHOR INFORMATION}

\section{Corresponding Author}

Jin Yu - Petroleum, Oil \& Lubricant Department, Army Logistical Academy, Chongqing 401331, China; The Green Aerotechnics Research Institute of Chongqing Jiaotong University, Chongqing 401120, China; School of Aeronautics, Chongqing Jiaotong University, Chongqing 400074, China; 다이.org/0000-0001-5695-6886; Email: yjin123@ yeah.net

\section{Authors}

Binbin Yu - Petroleum, Oil \& Lubricant Department, Army Logistical Academy, Chongqing 401331, China; (1) orcid.org/0000-0003-1702-6189 
Xinsheng Jiang - Petroleum, Oil \& Lubricant Department, Army Logistical Academy, Chongqing 401331, China

Donghai He - Petroleum, Oil \& Lubricant Department, Army Logistical Academy, Chongqing 401331, China

Chunhui Wang - Petroleum, Oil \& Lubricant Department, Army Logistical Academy, Chongqing 401331, China

Zituo Wang - Petroleum, Oil \& Lubricant Department, Army Logistical Academy, Chongqing 401331, China

Yunxiong Cai - Petroleum, Oil \& Lubricant Department, Army Logistical Academy, Chongqing 401331, China

Jia-jia Yu - School of Energy and Power Engineering, Chongqing University, Chongqing 400044, China; (1) orcid.org/0000-0002-2677-1933

Complete contact information is available at:

https://pubs.acs.org/10.1021/acsomega.1c03442

\section{Notes}

The authors declare no competing financial interest.

\section{ACKNOWLEDGMENTS}

This work was supported by the National Key R\&D Program of China (2018YFC0809500), Postgraduate Research Innovation Project of Chongqing (CYB20200), National Natural Science Foundation of China (51574254), Science and Technology Project of Chongqing (CSTC 2017jcycAX0132), and Open Fund of Chongqing Key Laboratory of Fire and Explosion Safety.

\section{REFERENCES}

(1) Li, H. X. The experiment on ignition characteristic and research on reaction kinetics of RP-3 kerosene; Shenyang Aerospace University, 2013.

(2) Zheng, D.; Yu, W.-M.; Zhong, B.-J. RP-3 aviation kerosene surrogate fuel and the chemical reaction kinetic model. Acta Phys.Chim. Sin. 2015, 31, 636-642.

(3) Fan, Q. M. Study on thermal stability of endothermic hydrocarbon fuels for hypersonic propulsion; Tianjing University, 2002.

(4) Saggese, C.; Wan, K.; Xu, R.; Tao, Y.; Wang, H. A physics-based approach to modeling real-fuel combustion chemistry - V. $\mathrm{NO}_{x}$ formation from a typical Jet A. Combust. Flame 2020, 212, 270-278.

(5) Zettervall, N.; Fureby, C.; Nilsson, E. J. K. A reduced chemical kinetic reaction mechanism for kerosene-air combustion. Fuel 2020, 269, 117446.

(6) Montgomery, C. J.; Cannon, S. M.; Mawid, M. A.; Sekar, B. Reduced chemical kinetic mechanisms for JP-8 combustion. AIAA Paper 2002, 336.

(7) Violi, A.; Yan, S.; Eddings, E. G.; Sarofim, A. F.; Granata, S.; Faravelli, T.; Ranzi, E. Experimental formulation and kinetic model for JP-8 surrogate mixtures. Combust. Sci. Technol. 2002, 174, 399-417.

(8) Starik, A. M.; Titova, N. S.; Torokhov, S. A. Kinetics of oxidation and combustion of complex hydrocarbon fuels: Aviation kerosene. Combust. Explo. Shock Power 2013, 49, 392-408.

(9) Yan, Y.; Liu, Y.; Di, D.; Dai, C.; Li, J. A simplified chemical reaction mechanism for surrogate fuel of aviation kerosene and its verification. Energy Fuels 2016, 30, 10847-10857.

(10) Zhang, C.; Li, B.; Rao, F.; Li, P.; Li, X. A shock tube study of the autoignition characteristics of RP-3 jet fuel. Proc. Combust. Inst. 2015, 35, 3151-3158.

(11) Zhong, B. J.; Peng, H. S. Development of a skeletal mechanism for aviation kerosene surrogate fuel. J. Propul. Power 2019, 35, 645651.

(12) Zheng, D.; Zhong, B.-J.; Yao, T. Methodology for formulating aviation kerosene surrogate fuels and the surrogate fuel model for HEF kerosene. Acta Phys.-Chim. Sin. 2017, 33, 2438-2445.
(13) Yi, R.; Chen, X.; Chen, C. P. Surrogate for emulating physicochemical and kinetics characteristics of rp-3 aviation fuel. Energy Fuels 2019, 33, 2872-2879.

(14) Zeng, W.; Liu, J.; Zhang, Z.; Hongan, M. A.; Zhang, J.; Liu, A. A new surrogate fuel of RP-3 Kerosene. J. Aerospace Power 2017, 32, 2314-2320.

(15) Zeng, P.; Wang, B. Y.; He, R. N.; Liang, J. H.; Yang, Z. Y.; Xia, Z. X.; Wang, Q. D. Single-pulse shock tube pyrolysis study of rp-3 jet fuel and kinetic modeling. ACS Omega 2021, 6, 11039-11047.

(16) Honnet, S.; Seshadri, K.; Niemann, U.; Peters, N. A surrogate fuel for kerosene. Proc.Combust. Inst. 2009, 32, 485-492.

(17) Dooley, S.; Won, S. H.; Heyne, J.; Farouk, I. T.; Ju, Y. G.; Dryer, L. F.; Kumar, T.; Hui, X.; Sung, C. J.; Wang, H. W.; et al. The experimental evaluation of a methodology for surrogate fuel formulation to emulate gas phase combustion kinetic phenomena. Combust. Flame 2012, 159, 1444-1466.

(18) Yu, J.; Wang, Z.; Zhuo, X.; Wang, W.; Gou, X. Surrogate definition and chemical kinetic modeling for two different jet aviation fuels. Energy Fuels 2016, 30, 1375-1382.

(19) Yu, J.; Ju, Y.; Gou, X. Surrogate fuel formulation for oxygenated and hydrocarbon fuels by using the molecular structures and functional groups. Fuel 2016, 166, 211-218.

(20) Yu, J. Studies on the surrogate fuel methods for the simulation of reacting flows in combustion; Chongqing University, 2017.

(21) Yu, J.; Yu, B. B.; Yu, J. J. Development of a comprehensive surrogate fuel for RP-3 kerosene. J. Aerospace Power 2020, 35, 673681.

(22) Cai, L.; Pitsch, H.; Mohamed, S. Y.; Raman, V.; Sarathy, S. M. Optimized reaction mechanism rate rules for ignition of normal alkanes. Combust. Flame 2016, 173, 468-482.

(23) Sarathy, S. M.; Javed, T.; Karsenty, F.; Heufer, A.; Wang, W.; Park, S.; Elwardany, A.; Farooq, A.; Westbrook, C. K.; Pitz, W. J.; Oehlschlaeger, M. A.; Dayma, G.; Curran, H. J.; Dagaut, P. A comprehensive combustion chemistry study of 2,5-dimethylhexane. Combust. Flame 2014, 161, 1444-1459.

(24) Kukkadapu, G.; Kang, D.; Wagnon, S. W.; Zhang, K.; Mehl, M.; Monge-Palacios, M.; Wang, H.; Goldsborough, S. S.; Westbrook, C. K.; Pitz, W. J. Kinetic modeling study of surrogate components for gasoline, jet and diesel fuels: C7-C11 methylated aromatics. Proc.Combust. Inst. 2019, 37, 521-529.

(25) Fang, X.; Huang, X.; Chen, W.; Qiao, X.; Ju, D. Development of a skeletal surrogate mechanism for emulating combustion characteristics of diesel from direct coal liquefaction. Combust. Flame 2020, 218, 84-97.

(26) Zhou, C. W.; Li, Y.; O’Conner, S. K. P.; Thion, S.; Keesee, C.; Mathieu, O.; Petersen, E. L.; DeVerter, T. A.; Oehlschlaeger, M. A.; et al. A comprehensive experimental and modeling study of isobutene oxidation. Combust. Flame 2016, 167, 353-379.

(27) Lu, T.; Law, C. K. A directed relation graph method for mechanism reduction. Proc. Combust. Inst. 2005, 30, 1333-1341.

(28) R. Design, Inc. CHEMKIN-PRO; Release 15101, in, Reaction Design, Inc.: San Diego, CA, 2010.

(29) Shen, H. P. S.; Steinberg, J.; Vanderover, J.; Oehlschlaeger, M. A. A shock tube study of the ignition of n-Heptane, n-Decane, nDodecane, and n-Tetradecane at elevated pressures. Energy Fuels 2009, 23, 2482-2489.

(30) Vasu, S. S.; Davidson, D. F.; Hong, Z.; Vasudevan, V.; Hanson, R. K. N-dodecane oxidation at high-pressures: Measurements of ignition delay times and $\mathrm{OH}$ concentration time-histories. Proc. Combust. Inst. 2009, 32, 173-180.

(31) Ji, C.; Dames, E.; Wang, Y. L.; Hai, W.; Egolfopoulos, F. N. Propagation and extinction of premixed C5-C12 n-alkane flames. Combust. Flame 2010, 157, 277-287.

(32) Dievart, P.; Kim, H. H.; Won, S. H. Y.; Dryer, F. L.; Dooley, S.; Wang, W.; Oehlschlaeger, M. A. The combustion properties of 1,3,5trimethylbenzene and a kinetic model. Fuel 2013, 109, 125-136.

(33) Zhu, Y.; Davidson, D. F.; Hanson, R. K. Pyrolysis and oxidation of decalin at elevated pressures: a shock-tube study. Combust. Flame 2014, 161, 371-383. 
(34) Oehlschlaeger, M. A.; Shen, H. P. S.; Frassoldati, A.; Pierucci, S.; Ranzi, E. Experimental and kinetic modeling study of the pyrolysis and oxidation of decalin. Energy Fuels 2009, 23, 1464-1472.

(35) Comandini, A.; Dubois, T.; Abid, S.; Chaumeix, N. Comparative study on cyclohexane and decalin oxidation. Energy Fuels 2014, 28, 714-724.

(36) Li, B.; Zhang, H.; Egolfopoulos, F. N. Laminar flame propagation of atmospheric iso-cetane/air and decalin/air mixtures. Combust. Flame 2014, 161, 154-161.

(37) Liu, Y.; Zeng, W.; Ma, H. A.; Chen, B. D. Combustion reaction mechanism of three-component simulation surrogate fuel for RP-3 kerosene. J. Aerospace Power 2016, 31, 2055-2064.

(38) Mao, Y.; Yu, L.; Wu, Z.; Tao, W.; Wang, S.; Ruan, C. Y.; Zhu, L.; Lu, X. Experimental and kinetic modeling study of ignition characteristics of RP-3 kerosene over low-to-high temperature ranges in a heated rapid compression machine and a heated shock tube. Combust. Flame 2019, 203, 157-169.

(39) Yang, Z.-Y.; Zeng, P.; Wang, B.-Y.; Jia, W.; Xia, Z.-X.; Liang, J.; Wang, Q.-D. Ignition characteristics of an alternative kerosene from direct coal liquefaction and its blends with conventional RP-3 jet fuel. Fuel 2021, 291, 120258.

(40) Liu, Y. X. The reaction kinetic studies of C9 surrogate fuels of kerosene; Chinese Academy of Sciences, 2019.

(41) Liu, Y.; Wang, J.; Gu, W.; Ma, H.; Zeng, W. An experiment study on the laminar burning velocity and markstein length of chlorella oil/RP-3 kerosene blends. ACS Omega 2020, 37, 2351023519 . 